\title{
EFFECT OF $\beta$-SILYL SUBSTITUTION OF THE REACTIVITY OF ELECTROPHILIC CARBENE COMPLEXES
}

\author{
Beverly George, Julie McClure, and Emma W. Goldman*
}

Department of Chemistry, University of Richmond, Richmond, VA 23173, USA

\begin{abstract}
A cationic B-silyl substituted carbene complex, $\left[\left(\eta^{5}-\mathrm{C}_{5} \mathrm{H}_{5}\right) \mathrm{Fe}(\mathrm{CO})\left(\mathrm{PPh}_{3}\right)=\mathrm{C}(\mathrm{OMe})-\right.$ $\left.\mathrm{CH}_{2} \mathrm{SiMe}_{3}\right]+\mathrm{BF}_{4}-$, was prepared by the reaction of trimethyloxonium tetrafluoroborate with the acyl complex, $\left(\eta^{5}-\mathrm{C}_{5} \mathrm{H}_{5}\right) \mathrm{Fe}(\mathrm{CO})\left(\mathrm{PPh}_{3}\right) \mathrm{C}(\mathrm{O}) \mathrm{CH}_{2} \mathrm{SiMe}_{3}$. Nucleophilic attack occurs at the silicon and not the electrophilic carbene carbon. Water and methanol react with the carbene complex to give the methylcarbene, $\left[\left(\eta^{5}-\mathrm{C}_{5} \mathrm{H}_{5}\right) \mathrm{Fe}(\mathrm{CO})\left(\mathrm{PPh}_{3}\right)=\mathrm{C}(\mathrm{OMe}) \mathrm{Me}\right]^{-\mathrm{BF}_{4}}$, and hexamethyldisiloxane and trimethylmethoxysilane, respectively.
\end{abstract}

\section{INTRODUCTION}

The $\beta$-effect of silicon has been widely investigated 1,2. The stabilization of $\beta$-silylcarbonium ions is "one of the most profound activating and directing effects" in organosilicon chemistry $1 \mathrm{a}$. The effect is due to the high polarizability and electropositive nature of silicon. Two mechanisms have been proposed: 1) a bridging intermediate (nonvertical) and 2) a vertical intermediate where the positive charge is stabilized via hyperconjugation $2 a$.

The $\beta$-effect of silicon in transition metal complexes has not been as well studied. However, by analogy to organosilicon chemistry, electrophilic centers in transition metal complexes should be stabilized by a $\beta$-silyl group. Fischer type carbene complexes are known to have electrophilic carbene carbons ${ }^{3}$. Heteroatoms such as oxygen, nitrogen, and sulfur have been found to stabilize these complexes through electron pair donation to the carbene carbon. As alluded to above, similar stabilization should be achieved by having a silyl group $B$ to the carbene carbon. We have recently been studying the reaction chemistry of $\left(\eta^{5}-\mathrm{C}_{5} \mathrm{H}_{5}\right) \mathrm{Fe}(\mathrm{CO})(\mathrm{L})-\mathrm{X}\left(\mathrm{L}=\mathrm{CO}\right.$ or $\left.\mathrm{PPh}_{3}\right)$ where $\mathrm{X}$ is either a silyl group directly bonded to iron 4 or an acyl group containing a $\beta$-silicon. To study the effect of a $\beta$-silyl group on the stability and reactivity of electrophilic carbene complexes we have prepared $\left(\eta^{5}-\mathrm{C}_{5} \mathrm{H}_{5}\right) \mathrm{Fe}(\mathrm{CO})\left(\mathrm{PPh}_{3}\right)-\mathrm{C}(\mathrm{O}) \mathrm{CH}_{2} \mathrm{SiMe}_{3}$ and report here results on the effect of a $\beta$-silicon group on the reactivity of iron acyl and carbene complexes.

\section{MATERIALS AND METHODS}

All synthetic manipulations were performed under a nitrogen atmosphere by using standard Schlenk techniques for handling air-sensitive compounds 5 or in a Dry Box. Solvents were distilled from either sodium benzophenone ketyl (THF, diethyl ether, hexane) or lithium aluminum hydride $\left(\mathrm{CH}_{2} \mathrm{Cl}_{2}\right)$ immediately prior to use. Infrared spectra were recorded on a Nicolet 5DX spectrophotometer. NMR spectra were recorded on either a GE Omega $300 \mathrm{MHz}$ or Varian Gemini $200 \mathrm{MHz}$ spectrometer. Chemical shifts were reported downfield from internal tetramethylsilane. GC-MS were obtained on a HP 5890 operating at $70 \mathrm{eV}$.

$\left(\eta^{5}-\mathrm{C}_{5} \mathrm{H}_{5}\right) \mathrm{Fe}(\mathrm{CO})\left(\mathrm{PPh}_{3}\right) \mathrm{C}(\mathrm{O}) \mathrm{CH}_{2} \mathrm{SiMe}_{3}$ was prepared according to literature procedures 6 . Trimethyloxonium tetrafluoroborate and $\mathrm{CD}_{2} \mathrm{Cl}_{2}$ were purchased from Aldrich and transferred in a Dry Box. 


\section{Preparation of $\left[\left(\eta^{5}-\mathrm{C}_{5} \mathrm{H}_{5}\right) \mathrm{Fe}(\mathrm{CO})\left(\mathrm{PPh}_{3}\right)=\mathrm{C}(\mathrm{OMe}) \mathrm{CH}_{2} \mathrm{SIMe}_{3}\right]+\mathrm{BF}_{4^{-}}, 1$}

Trimethyloxonium tetrafluoroborate $(0.50 \mathrm{~g}, 2.6 \mathrm{mmol})$ was added to a solution of $\left(n^{5}-\mathrm{C}_{5} \mathrm{H}_{5}\right) \mathrm{Fe}(\mathrm{CO})\left(\mathrm{PPh}_{3}\right)-\mathrm{C}(\mathrm{O}) \mathrm{CH}_{2} \mathrm{SiMe}_{3}(1.36 \mathrm{~g}, 2.6 \mathrm{mmol})$ in $2 \mathrm{~mL}$ of $\mathrm{CH}_{2} \mathrm{Cl}_{2}$ in a Dry Box. The mixture was allowed to stir at room temperature for $12 \mathrm{~h}$. The solution was concentrated and added dropwise to diethyl ether. A yellow solid $(1.1 \mathrm{~g}, 76 \%)$ formed which was characterized as the methylcarbene complex, $\left[\left(\eta^{5}-\mathrm{C}_{5} \mathrm{H}_{5}\right) \mathrm{Fe}(\mathrm{CO})\left(\mathrm{PPh}_{3}\right)=\mathrm{C}(\mathrm{OMe}) \mathrm{Me}\right]^{+} \mathrm{BF}_{4} \cdot$ by comparison of its ${ }^{1} \mathrm{H}$ and ${ }^{13} \mathrm{C}$ NMR, and IR spectra with that of an authentic sample.

The reaction was repeated and quenched with either water or methanol. In these cases the volatiles were removed by trap-to-trap distillation and analyzed by gc-ms. Hexamethyldisiloxane was found to be present in both reactions and trimethylmethoxysilane was also found to be present in the reaction with methanol.

\section{RESULTS}

In order to prepare the carbene complex, 1 , trimethyloxonium tetrafluoro-borate was added to a solution of $\left(\eta^{5}-\mathrm{C}_{5} \mathrm{H}_{5}\right)(\mathrm{CO})\left(\mathrm{PPh}_{3}\right) \mathrm{FeC}(\mathrm{O}) \mathrm{CH}_{2} \mathrm{SiMe}_{3}, 2$, in methylene chloride. A yellow solid was isolated and characterized as the methoxymethylcarbene complex, 3 , by comparison of its ${ }^{1} \mathrm{H}$ and ${ }^{13} \mathrm{C}$ NMR and IR spectra with those of an authentic sample.

Complex 3 could be formed in two possible manners as outlined in Figure 1 below. One possibility is that complex 2 is methylated by the trimethyloxonium tetrafluoroborate to prepare the $\beta$-silyl carbene complex 1 followed by cleavage of the silyl group (pathway A). Altematively, the silyl group could be cleaved prior to methylation (pathway B).

\section{Figure 1}

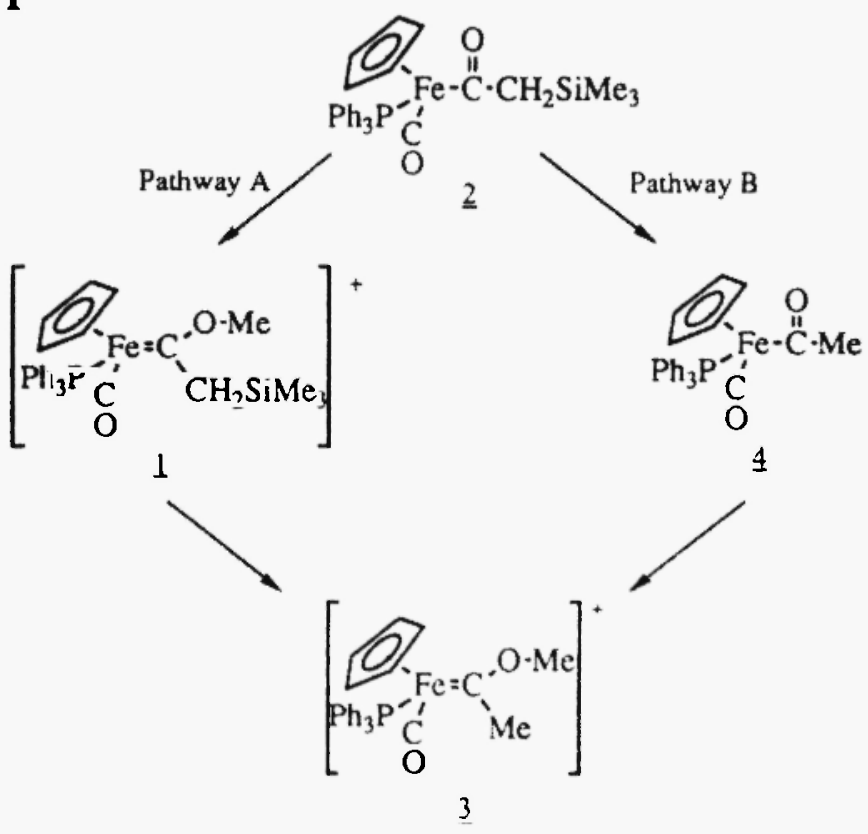


In order to investigate further the formation of the methoxymethylcarbene complex, $\mathbf{3}$, we have monitored the reaction of 2 with trimethyloxonium tetrafluoroborate by ${ }^{1} \mathrm{H}$ and ${ }^{13} \mathrm{C} N M R$ spectroscopy, and quenched the reaction solutions with methanol or water followed by analysis of the reaction products.

NMR spectroscopy was supportive but not definitive in showing that compound 1 was being formed. For instance, when the reaction was followed at room temperature by ${ }^{1} \mathrm{H}$ NMR spectroscopy, new peaks were observed at $\delta 0.212$ and $0.248(\mathrm{SiMe}), 2.76\left(\mathrm{CH}_{2}\right), 3.28(\mathrm{MeOMe}), 3.94(\mathrm{OMe})$, and $4.92(\mathrm{Cp})$. In the ${ }^{13} \mathrm{C}$ NMR spectrum new peaks were observed at $\delta 0.33,0.64(\mathrm{SiMe}), 46.2\left(\mathrm{CH}_{2}\right)$, $60.9(\mathrm{MeOMe}), 65.7(\mathrm{OMe})$, and $88.59(\mathrm{Cp})^{7}$. These chemical shifts (except for the silylmethyl peaks) are very similar to the peaks observed for the methylcarbene, 3.8 This is not surprising since the chemical shifts for the Cp's in the iron acyl complexes 2 and 4 are also similar appearing at $\delta 4.42$ and 4.45 in the ${ }^{1 H}$ NMR spectrum and $\delta 86.0$ and 86.8 in the ${ }^{13} \mathrm{C}$ NMR spectrum, respectively.

To give further evidence of the formation of 1 , the reaction with trimethyloxonium tetrafluoroborate was repeated and quenched with either methanol or water. GC-MS analysis of the reaction solution before quenching showed that a small amount of hexamethyldisiloxane was present but after quenching with water a substantial amount of hexamethyldisiloxane was observed. Likewise before quenching with methanol, a small amount of hexamethyldisiloxane was observed by GC-MS, but after quenching trimethylmethoxysilane was the main product observed by GC-MS. The iron containing product in both cases was the methoxymethylcarbene, 3 . This can be explained by initial formation of 1 , where either water or methanol act as nucleophiles attacking the silane. In many of the reactions a small amount of 4 was observed (less than $5 \%$ by NMR spectroscopy) and isolated. It is known that $\mathrm{HCl}$ can cleave the $\mathrm{C}$-Si bond in 2 to form $\underline{4}$. Similarly in these reactions $\mathrm{HBF}_{4}$, which is a known contaminant in trimethyloxonium tetrafluoroborate ${ }^{8}$, could cleave the $\mathrm{C}$-Si bond to form 4 . If pathway $B$ were the main reaction process occurring, it would be expected that larger amounts of 4 would be observed while monitoring the reaction by NMR spectroscopy. The reaction of either 2 or 4 with trimethyloxonium tetrafluoroborate is slow, taking about 12 hours to occur, largely because the trimethyloxonium tetrafluoroborate is only slightly soluble in methylene chloride.

\section{DISCUSSION}

Electrophilic heteroatom-stabilized carbene complexes, such as $\underline{\mathbf{3}}$ react with nucleophiles in a variety of ways 9.10 . Some reagents, such as sodium borohydride or lithium triethylborohydride, react at the carbene carbon to yield an $\alpha$-ether complex. Reaction with alkoxide ions occurs at the $\alpha$-carbon, abstracting a proton to form a vinyl ether. In some cases, a small amount of ketal product resulting from attack of the alkoxide at the carbene carbon has been observed. Reaction of $\underline{3}$ with $\mathrm{Nal}$ leads to the elimination of $\mathrm{Mel}$ and formation of the acyl complex. Complex $\mathbf{3}$ is moisture and air-stable, i.e., it does not react with water or alcohols. The presence of the $\beta$-silyl group has a major effect on the reactivity of 1 and this observation may be related to known organosilicon reactivity.

Allylsilanes are reactive to electrophilic attack to form selectively $\beta$-silyl substituted carbocations which then react with nucleophiles to eliminate the silyl group (Figure 2$)^{10}$. Compound 1 can be compared to the intermediate in these reactions.

Figure 2

$$
\mathrm{Me}_{3} \mathrm{Si} \frown \stackrel{\mathrm{E}^{+}}{\longrightarrow} \mathrm{Me}_{3} \mathrm{Si} \frown \overbrace{} \stackrel{\mathrm{Nu}^{\circ}}{\longrightarrow} \mathrm{Me}_{3} \mathrm{SiNu}+\frown \mathrm{E}
$$


Although the NMR spectra are inconclusive in proving that pathway $A$ is the main reaction process, the formation of hexamethyldisiloxane and trimethylmethoxysilane after quenching with water and methanol respectively, gives evidence that carbene complex 1 is being formed. Compound 1 is more reactive toward nucleophiles than its corresponding methyl analog. The $\beta$-effect of silicon should stabilize the electrophilic carbene, but in the process the silyl group is easily attacked by nucleophiles. Further work is being done to study the $\beta$-effect of silicon in other carbene complexes and transition metal complexes with electrophilic centers. For example, other reagents such as methyl triflate ${ }^{91}$ and $\left(\mathrm{MeO}_{2} \mathrm{CHPF}_{6}{ }^{8}\right.$ have been used to methylate metal acyl complexes and these are being tried.

ACKNOWLEDGEMENTS: Acknowledgement is made to the donors of the Petroleum Research Fund, administered by the American Chemical Society, for support of this work.

\section{REFERENCES}

1. For reviews of the $\beta$-effect of silicon, see a) "Activating and Directive Effects of Silicon" In The Chemistry of Organic Silicon Compounds; Patai, S. , Rappoport, Z., Eds. Wiley: New York, 1989; Vol. 2, Chapter 14. b) "Organosilanes", In Comprehensive Organometallic Chemistry, Wilkinson, G.; Stone, F. G. A.; and Abel, E.W., Eds.; Pergamon Press: Oxtord, 1982; Vol. 2, Chapter 9.

c) Lambert, J. B. Tetrahedron (1990), 46, 2677.

2. Recent articles describing the effect include a) Nguyen, K. A.; Gordon, M. S.; Wang, G.; Lambert, J. B. Organometallics (1991), 10, 2798. b) Dallaire, C.; Brook, M. A. Organometallics (1990), 9, 2873, and references therein.

3. For reviews on transition metal carbenes see a) Cardin, D. J.; Cetinkaya, B.; Lappert, M. F. Chem. Rev. (1972), 72, 545 . b) Cotton, F.A.; Lukehart, C. M. Prog. Inorg. Chem. (1972), 16, 487.

c) Casey, C. P. In Reactive Intermediates, Jones, M., Moss, R. A., Eds.; Wiley: New York, 1981; Vol. 2, Chapter 4, p 135. d) Casey, C. P. CHEMTECH 1979, 378.

4. Results submitted for publication.

5. a) King, R. B. In Organomet. Syn., Academic Press, New York, 1965, Vol 1.

b) Shriver, D. F. In Manipulation of Air-Sensitive Compounds, McGrawHill, New York, 1969.

6. a) Pannell, K. H. Transition Met. Chem. (1975), 1, 36. b) Pannell, K. H. J. Organomet. Chem. (1970), 21, P17.

7. It was not possible to definitively assign carbonyl and carbene signals in the ${ }^{13} \mathrm{C}$ NMR spectrum.

8. Bodnar, T. W.; Cutler, A. R. Syn. React. Inorg. Met.-Org. Chem. (1985), 15, 31.

9. a) Davison, A.; Reger, D. J. Am. Chem. Soc. (1972), 94, 9237. b) Cutler, A. R. J. Am. Chem. Soc. (1979), 101, 604. c) Bodnar, T.; Cutler, A. R. J. Organomet. Chem. (1981), 213, C31.

d) Casey, C. P.; Tukada, H.; Miles, W. H. Organometallics (1982), 1, $1083 . \quad$ e) Casey, C. P.; Miles W. H.; Tukada, H.; O'Connor, J. M. J. Am. Chem. Soc. (1982), 104, 3761. f) Brookhart, M.; Tucker, J. R.; Husk, G. R. J. Am. Chem. Soc. (1983), 105, 258.

10. "Organosilicon Compounds in Organic Synthesis", in Comprehensive Organometallic Chemistry, Wilkinson, G.; Stone, F. G. A.; and Abel, E.W., Eds.; Pergamon Press: Oxford, 1982; Vol. 7, Chapter 48, p 518.

Received: August 4, 1993 - Accepted: September 10, 1993 Accepted in revised camera-ready format: October 5, 1993 